\title{
Randomized controlled study using text messages to help connect new medicaid beneficiaries to primary care
}

\author{
David M. Levine $\mathbb{1}^{1,2 凶}$, Pragya Kakani ${ }^{2,3}$ and Ateev Mehrotra ${ }^{2,3,4}$
}

Accessing primary care is often difficult for newly insured Medicaid beneficiaries. Tailored text messages may help patients navigate the health system and initiate care with a primary care physician. We conducted a randomized controlled trial of tailored text messages with newly enrolled Medicaid managed care beneficiaries. Text messages included education about the importance of primary care, reminders to obtain an appointment, and resources to help schedule an appointment. Within 120 days of enrollment, we examined completion of at least one primary care visit and use of the emergency department. Within 1 year of enrollment, we examined diagnosis of a chronic disease, receipt of preventive care, and use of the emergency department. 8432 beneficiaries (4201 texting group; 4231 control group) were randomized; mean age was 37 years and $24 \%$ were White. In the texting group, $31 \%$ engaged with text messages. In the texting vs control group after 120 days, there were no differences in having one or more primary care visits ( $44.9 \%$ vs. $45.2 \%$; difference, $-0.27 \%$; $p=0.802)$ or emergency department use $(16.2 \%$ vs. $16.0 \%$; difference, $0.23 \% ; p=0.771)$. After 1 year, there were no differences in diagnosis of a chronic disease $(29.0 \%$ vs. $27.8 \%$; difference, $1.2 \% ; p=$ 0.213 ) or appropriate preventive care (for example, diabetes screening: $14.1 \%$ vs. $13.4 \%$; difference, $0.69 \% ; p=0.357$ ), but emergency department use $(32.7 \%$ vs. $30.2 \%$; difference, $2.5 \% ; p=0.014)$ was greater in the texting group. Tailored text messages were ineffective in helping new Medicaid beneficiaries visit primary care within 120 days.

npj Digital Medicine (2021)4:26; https://doi.org/10.1038/s41746-021-00389-5

\section{INTRODUCTION}

Primary care use-care that is first-contact, comprehensive, coordinated, and continuous ${ }^{1,2}$-is associated with better quality, better care experience, and increased life expectancy ${ }^{3,4}$. Engaging with a new primary care provider (PCP) can be difficult, particularly for patients with Medicaid ${ }^{5,6}$. A key moment of opportunity, but also of confusion, occurs when beneficiaries enroll in a new plan. New beneficiaries may not understand which PCPs are in the plan's network or how to contact an assigned $\mathrm{PCP}^{7}$. Compared to those with commercial insurance, Medicaid enrollees are less likely to have a PCP over time ${ }^{8}$ and in some communities few PCPs accept Medicaid ${ }^{9}$. Studies of Medicaid expansion have found that there are increases in emergency department (ED) use ${ }^{10,11}$, which is attributed partly to the inability for new enrollees to engage with primary care. Helping new Medicaid beneficiaries obtain a PCP remains a major challenge ${ }^{5,12}$.

One potential intervention to increase PCP use is text messages. In prior work, though the effects are not always consistent, text messages decreased no-show rates in clinics $^{13-16}$, including in underserved populations ${ }^{17,18}$. Given $95 \%$ of low-income Americans own a cell phone (71\% own a smartphone), text messages are becoming ubiquitous and therefore may be a lower-cost, more convenient, and more effective mechanism to reach this underserved population over phone calls or mail ${ }^{19}$. A new development is the use of automated tailored text messages in which a computer uses an algorithm to respond to typical questions or responses from patients. This allows for a relatively lower cost, but still a "higher touch" and personalized experience. Whether tailored text messages can help newly enrolled patients engage with primary care within 120 days after enrollment is unknown.
In a randomized control trial we test the effect of tailored text messages on visiting primary care within 120 days of enrollment into a Medicaid plan.

\section{RESULTS}

\section{Participant characteristics}

After our exclusion criteria there were 8432 newly enrolled beneficiaries randomized (4201 texting group; 4231 control group; Fig. 1 and Table 1). Over half (55.8\%) were female with a mean age of 37.0 years. Most (89.0\%) spoke English. Many (47.3\%) were Hispanic, while $23.9 \%$ were White, $10.3 \%$ were Black, and $10.8 \%$ were of unknown race/ethnicity. There were no meaningful differences between the two groups at baseline on the measured characteristics. Within 1 year, $30.7 \%$ of the texting group and $31.7 \%$ of the control group had disenrolled from the plan (difference, $-1.0 \% ; 95 \% \mathrm{Cl},-2.7 \%$ to $0.6 \% ; p=0.22$ ).

Of the 4201 beneficiaries in the texting group, 2116 (50.4\%) replied in some form to the initial text message, 1305 beneficiaries (31.1\%) responded with a response other than "stop", and 432 beneficiaries (10.3\%) responded more than four times with a response other than stop. Beneficiaries in the texting arm who engaged with the texts (i.e., responded with a response other than "stop") were older, more likely to be female, and less likely to be Hispanic than those in the texting arm who did not engage with the texts (Supplementary Table 2).

\section{Engagement with primary care within 120 days}

At 120 days, $44.9 \%$ of the texting group and $45.2 \%$ of the control group had one or more primary care visits (difference, $-0.27 \%$; $95 \% \mathrm{Cl},-0.94$ to $0.41 \% ; p=0.44$; Table 2 ). Completion of the IHA

${ }^{1}$ Division of General Internal Medicine and Primary Care, Brigham and Women's Hospital, Boston, MA, USA. ${ }^{2}$ Harvard Medical School, Boston, MA, USA. ${ }^{3}$ Department of Health Care Policy, Harvard Medical School, Boston, MA, USA. ${ }^{4}$ Division of General Medicine, Beth Israel Deaconess Medical Center, Boston, MA, USA. ${ }^{\circledR}$ email: dmlevine@bwh.harvard.edu 


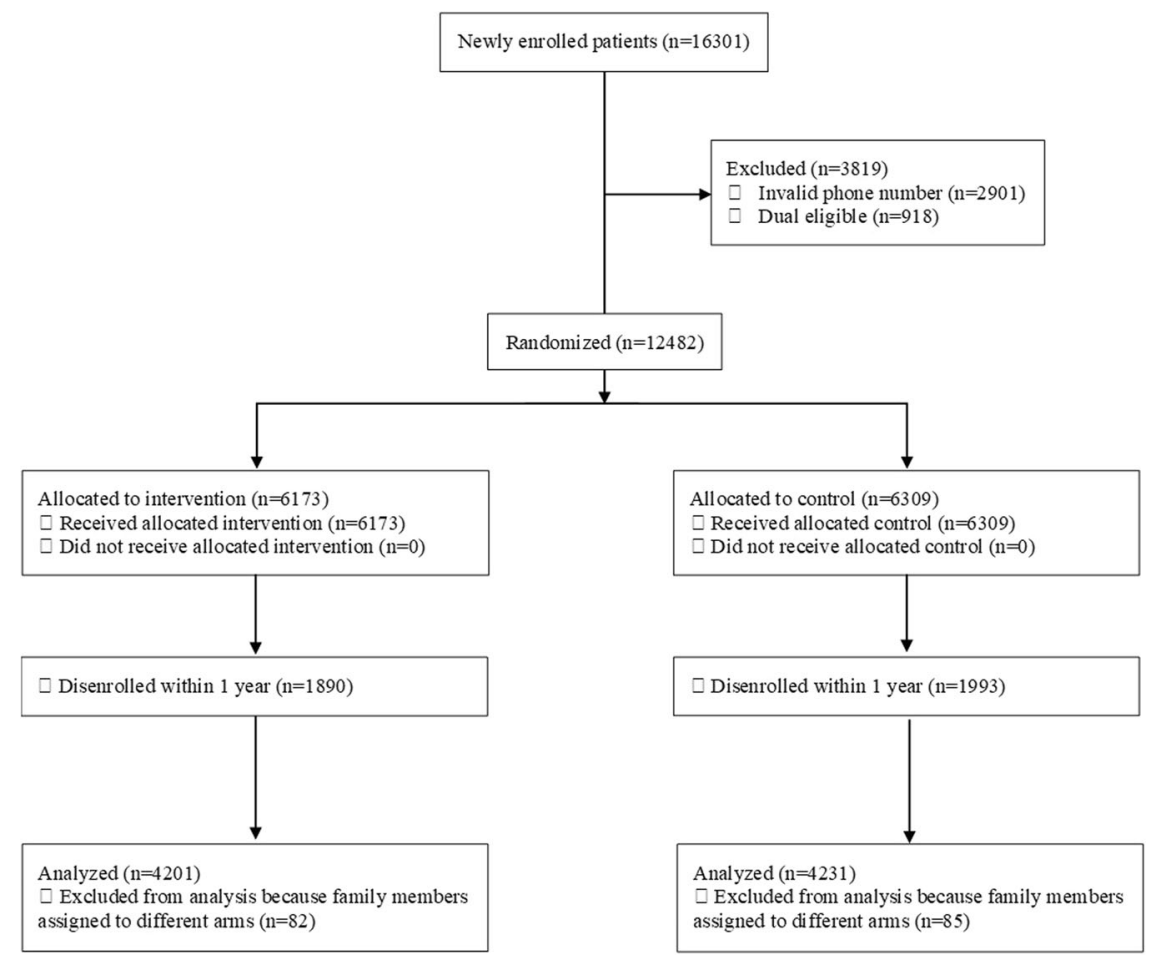

Fig. 1 Participant flow. The Consolidated Standards of Reporting Trials flow diagram.

\begin{tabular}{|c|c|c|}
\hline & Control $(n=4231)$ & Texting $(n=4201)$ \\
\hline Age, mean $(95 \% \mathrm{Cl})$ & $36.9(36.5,37.3)$ & $37.1(36.7,37.6)$ \\
\hline Female, $n(\%)^{\mathrm{a}}$ & $2374(56.1 \%)$ & $2326(55.4 \%)$ \\
\hline English is first language, $n$ (\%) & 3736 (89.0\%) & $3741(89.1 \%)$ \\
\hline \multicolumn{3}{|l|}{ Race/ethnicity, n (\%) } \\
\hline White & $1005(23.7 \%)$ & 1007 (24.0\%) \\
\hline Black & 449 (10.6\%) & 417 (9.9\%) \\
\hline Hispanic & $1993(47.1 \%)$ & 1996 (47.5\%) \\
\hline Other & 328 (7.7\%) & 325 (7.7\%) \\
\hline Unknown & $456(10.8 \%)$ & $456(10.8 \%)$ \\
\hline
\end{tabular}

was also similar: $44.8 \%$ in the texting group and $45.0 \%$ in the control group (difference, $-0.25 \% ; 95 \% \mathrm{Cl},-2.37$ to $1.87 \% ; p=$ 0.82).

\section{Identification of chronic disease and preventive testing}

At 1 year, identification of chronic disease was similar in the texting vs. control group: $29.0 \%$ vs. $27.8 \%$ (difference, $1.2 \%$; $95 \%$ $\mathrm{Cl},-0.7$ to $3.1 \% ; p=0.21$; Table 2 ). The most commonly identified chronic diseases were hypertension (14.3\% texting vs. $13.6 \%$ controls), depression ( $9.7 \%$ vs. $8.9 \%)$, and diabetes ( $8.7 \%$ vs. $8.3 \%$ ). There was no difference in frequency of identification for any chronic disease between the two groups.

At 1 year, receipt of preventive testing was not different in the texting versus control group, including diabetes screening $(14.1 \%$ vs. $13.4 \%$; difference, $0.69 \% ; 95 \% \mathrm{Cl},-0.8 \%$ to $2.2 \% ; p=0.36)$ and cholesterol screening (34.3\% vs. $33.5 \%$; difference, $-0.42 \%$; $95 \%$ $\mathrm{Cl},-0.6$ to $1.4 \% ; p=0.41$; Table 2 ).

\section{Emergency department utilization}

At 120 days in the text message vs. control group, emergency department use at least once $(16.2 \%$ vs. $16.0 \%$; difference, $0.23 \%$; $95 \% \mathrm{Cl},-1.33$ to $1.8 \% ; p=0.77)$ or for avoidable use $(2.5 \%$ vs. $2.7 \%$ difference, $-0.27 \% ; 95 \% \mathrm{Cl},-0.94$ to $0.41 \% ; p=0.44$ ) was not significantly different. At 1 year, use of the emergency department at least once was higher in the text message group (32.7\% vs. $30.2 \%$; difference, $2.5 \%$; $95 \% \mathrm{Cl}, 0.5$ to $4.5 \% ; p=0.014$; Table 2). Avoidable emergency department use at least once (6.1\% vs. $5.7 \%$ ) was not statistically different (difference, $0.4 \% ; 95 \%$ $\mathrm{Cl},-0.6$ to $1.4 \% ; p=0.41)$.

\section{Instrumental variable analysis}

The results were overall similar in our instrumental variable sensitivity analysis (Table 2). The magnitude of all effects was larger as estimated by instrumental variable analysis, but all estimated effects were statistically insignificant, with the exception of ED use, as found in the intention-to-treat analysis. In the instrumental variable analysis, the text messaging intervention increased ED use by $9.0 \%(p=0.01)$ among patients who engaged with text messages and did not opt out.

\section{DISCUSSION}

Newly enrolled Medicaid beneficiaries who received tailored text messages encouraging them to visit primary care were not more likely to visit primary care within 120 days, receive preventive services, or obtain a diagnosis of a chronic disease. However, enrollees randomized to text messages were more likely to use the emergency department over a year.

There are several possible explanations for why text messages did not cause increased use of primary care. First, despite the support provided by the text messages, perhaps it was insufficient to surmount the barriers many beneficiaries face to make their first primary care appointment happen within 120 days $^{12,20}$. For example, perhaps transportation to clinic or challenging work schedules prevented patients from receiving care. It is also 
Table 2. Text message outcomes.

\begin{tabular}{|c|c|c|c|c|c|c|}
\hline & \multirow{2}{*}{$\begin{array}{l}\text { Control }(n=4231) \\
n(\%)\end{array}$} & \multirow{2}{*}{$\begin{array}{l}\text { Texting }(n=4201) \\
n(\%)\end{array}$} & \multicolumn{2}{|c|}{ Intention-to-treat analysis } & \multicolumn{2}{|c|}{$\begin{array}{l}\text { Instrumental variable } \\
\text { analysis }\end{array}$} \\
\hline & & & Difference (\%) & $p$-value & Difference (\%) & $p$-value \\
\hline Primary care visit & $1913(45.2)$ & $1888(44.9)$ & -0.27 & 0.80 & -0.88 & 0.80 \\
\hline IHA completion & $1906(45.0)$ & $1882(44.8)$ & -0.25 & 0.82 & -0.80 & 0.82 \\
\hline \multicolumn{7}{|l|}{ Outcomes captured at 1 year } \\
\hline Primary care change & $2309(54.6)$ & $2302(54.8)$ & 0.22 & 0.84 & 0.72 & 0.84 \\
\hline Emergency visit & $1279(30.2)$ & $1374(32.7)$ & 2.48 & 0.01 & 8.97 & 0.01 \\
\hline Avoidable emergency visit & $241(5.7)$ & $257(6.1)$ & 0.42 & 0.41 & 1.36 & 0.41 \\
\hline \multicolumn{7}{|l|}{ Preventive management } \\
\hline Any illness & $1176(27.8)$ & $1219(29.0)$ & 1.22 & 0.21 & 3.93 & 0.21 \\
\hline Asthma & $192(4.5)$ & $221(5.3)$ & 0.72 & 0.12 & 2.33 & 0.12 \\
\hline COPD & $16(0.4)$ & $13(0.3)$ & -0.07 & 0.59 & -0.22 & 0.59 \\
\hline Depression & $375(8.9)$ & $409(9.7)$ & 0.87 & 0.17 & 2.81 & 0.17 \\
\hline Diabetes & $353(8.3)$ & $364(8.7)$ & 0.32 & 0.60 & 1.03 & 0.60 \\
\hline Dyslipidemia & $308(7.3)$ & $325(7.7)$ & 0.46 & 0.43 & 1.47 & 0.43 \\
\hline Hypertension & $575(13.6)$ & $601(14.3)$ & 0.72 & 0.34 & 2.30 & 0.34 \\
\hline Ischemic heart disease & $90(2.1)$ & $98(2.3)$ & 0.21 & 0.52 & 0.66 & 0.52 \\
\hline
\end{tabular}

possible that the text messages did trigger enrollees to schedule an appointment, but local PCPs had limited appointment availability. Or perhaps the text messaging intervention was not sufficiently personalized, for example able to suggest a local PCP with greater appointment availability. Second, text messages may be insufficient to drive younger adults who are not ill and do not perceive a need to visit a physician ${ }^{21}$.

Our work builds on and corroborates others. Prior work in a safety net population demonstrated that patients had access to and preferred text messages over e-mail, phone, and letters for communication $^{22}$. While there are studies demonstrating text messages are effective, others have not found any benefit. For example, condition-specific text messages have had a limited effect $^{23-27}$ and one study found text messages may be no better, except with regard to cost, than other outreach such as phone in reducing no-show rates ${ }^{28}$.

Multiple avenues may improve the efficacy of text messages. First, several groups have advocated following cultural relevancy principles for text messages ${ }^{29,30}$. This could also include involving patients and clinicians in the creation and usability testing of the messages. Second, text messages could be tied to financial incentives. For example, offering an incentive for participation linked to a loss aversion schema that requires a certain number of responses may lead to higher engagement ${ }^{31}$. Third, the text messages could be bundled with more support. Patients in a local health care delivery area could be asked about the major barriers they find when attempting to access primary care. If, for example, wait time or language concordance when attempting to schedule an appointment on the phone were barriers, instead of encouraging patients to schedule an appointment with primary care, the text message system could offer to schedule it for them.

One unexpected finding was that the intervention led to an increase in total ED visits at 1 year, but not at 120 days nor for avoidable ED admissions. What underlies this is unclear. Possibly the text messages reminded them of their insurance coverage in general, and when a health issue arose later in the year, this prompted an ED visit when other opportunities for care were not as easily available. This finding requires replication.

Our study has limitations. First, the intervention only had fair uptake, with about $31 \%$ of beneficiaries engaging in 1 text message response $\mathrm{e}^{32-34}$. It is possible that with more uptake, results would have differed, though in our sensitivity analysis that addressed engagement we found no substantive differences. Second, we used administrative data, which does not contain rich sociodemographic data. It is possible that despite randomization, unobserved confounding existed between the two groups. In addition, these beneficiaries were new to the Medicaid plan, so we could not ascertain prior utilization or medical comorbidities. Third, about 30\% disenrolled from the plan and 18\% were excluded because of an invalid phone number. While this mirrors other Medicaid plan experiences, this could have confounded differences between the two groups ${ }^{35}$. Fourth, we analyzed text messages at 1 Medicaid managed care plan, limiting generalizability. Fifth, our analysis could not rule out supply-side constraints as driving our null finding, as discussed above.

Tailored text messages to new Medicaid beneficiaries were ineffective in increasing use of primary care within 120 days but increased ED utilization over 1 year.

\section{METHODS}

\section{Context and overview}

Since 2008, to encourage more enrollees to obtain primary care, the California Department of Healthcare Services has required all Medicaid managed care plans to ensure that members undertake an initial health assessment (IHA) by their PCPs within 120 days of enrollment ${ }^{36}$. The IHA is 
a comprehensive assessment of physical and emotional health that catalogs appropriate preventive care and delineates a care plan that is done by a PCP during a visit. As a result of this mandate, the Medicaid managed care plan with which we partnered was interested in whether a low-cost text message platform could help newly enrolled beneficiaries engage in primary care within 120 days, with potential downstream benefits including use of preventive care, identification of chronic illness, and reducing emergency department utilization.

The Medicaid managed care plan collaborated with a private vendor specializing in text messages for health plans to offer tailored text messages to newly enrolled beneficiaries. The plan and vendor designed and implemented the randomized controlled trial. We performed a retrospective evaluation of their parallel-design, randomized controlled trial with participants randomly allocated to tailored text messages and traditional new member communication (intervention) versus traditional new member communication alone (control). Participants were enrolled between June 7, 2018 and August 7, 2018; follow-up ended July 30, 2019. The Medicaid plan did not have access to which enrollees were randomized to the intervention and the text message company did not have access to the outcome data. We independently merged and analyzed data from both entities.

The retrospective evaluation was approved by the Harvard Medical School Institutional Review Board as exempt. Because this was a quality improvement initiative of the Medicaid plan, users did not provide informed consent but did sign their standard beneficiary agreement and could opt out of text messages upon receipt of the first message. There was no contact with the users beyond the text messages.

\section{Setting and participants}

Participants were all newly insured adult ( $\geq 18$ years old) beneficiaries of a large, mostly urban, California Medicaid managed care health insurance plan who were newly enrolled during the above dates. The plan was only available to residents of select California counties ${ }^{37}$. Participants were excluded if they carried an "administrative label" given access would be different for this group, which occurred when a beneficiary had Medicaid with a share-of-cost requirement, resided in a long-term care facility, had other health insurance and Medicaid was only for secondary coverage, were enrolled under a special aid category, or were in hospice.

\section{Randomization}

Each month, the Medicaid plan provided the text message company with the telephone numbers of newly enrolled beneficiaries. The text message company would scrub this list, excluding those without a valid cell phone number that accepts text messages (18\% excluded). The text message company randomized remaining telephone numbers 1:1 to either receive their tailored text message program or receive usual care (no text messages). If two or more individuals were randomized in the same household to different arms, we retrospectively excluded all individuals in the household to prevent contamination (1.8\% dropped individuals).

\section{Intervention}

The tailored text messages were delivered during a 16-week program. Tailoring occurred around primary language, age, sex, and other proprietary algorithms. Participants received at least five messages per month. The system delivered information via text and was able to respond to participant free-text responses using natural language processing. During weeks $1-4$, beneficiaries were welcomed, assessed for baseline knowledge regarding how to obtain primary care, and educated regarding the IHA. During weeks 5-14, beneficiaries were asked to schedule their first appointment with a PCP. They also received tailored messages on how to access a nurse advice line, behavioral health resources, and dental benefits. To encourage engagement with the text messaging service, they also received messages regarding wellness, air quality, and food insecurity. During weeks 15 and 16, their knowledge of how to get care was assessed. In both arms, the Medicaid plan sent its standard mailings to all new beneficiaries describing how to access benefits. Usual care received only these mailings. At any time, beneficiaries could cease participation.

\section{Outcomes and follow-up}

All outcome data were obtained from the health plan's administrative data or the text message company. Our primary outcome was completion of one or more primary care visits within 120 days of enrollment. A secondary outcome was receipt of the IHA within 120 days of enrollment. The norm is that this is completed at the primary care office, but some offices may not complete the IHA. We therefore report PCP IHA completion rates, which were similar in both groups (Supplementary Note). We examined engagement with text messages by noting to how many text messages a participant responded (with a response other than stop).

We also examined other outcomes that could be impacted by increased receipt of primary care. Our secondary outcomes included 1-year receipt of preventive care (hemoglobin A1c or lipid panel) and diagnosis of a chronic disease (asthma, chronic obstructive pulmonary disease, depression, diabetes, dyslipidemia, hypertension, or ischemic heart disease). We counted a single visit with relevant ICD-10 code as evidence of chronic disease. We also captured the rates of disenrollment with the health plan. Finally, we examined at both 120 days and 1 year the use of the emergency department and avoidable use of the emergency department (Supplementary Table 1).

\section{Statistical analysis}

We present descriptive data on sociodemographics, engagement, and disenrollment with counts and percentages or means and $95 \%$ confidence intervals as appropriate. We first present differences in outcomes between all patients in the treatment and control group, also known as an intentionto-treat estimate. A standard intention to treat analysis estimates the effect of recommending a treatment, not the effect of the treatment on those who received $\mathrm{it}^{38}$. In this case, the intention-to-treat estimate is the estimated effect of being assigned to receive text messaging.

As a sensitivity analysis, we also used an instrumental variable analysis to address the limited engagement rate among patients to the text messaging intervention. Increasingly used in clinical trials, the instrumental variable analysis estimates the impact of the text messaging intervention among the patients who engaged ${ }^{38,39}$. We defined engagement as patients who responded to the text message at least once and did not opt out by saying "stop" at any point in the study period. The instrument was treatment assignment.

We performed all analyses with Stata version 15.1 (College Station, TX, USA). We considered two-sided $p$-values of $<0.05$ to be significant.

\section{Reporting summary}

Further information on experimental design is available in the Nature Research Reporting Summary linked to this paper.

\section{DATA AVAILABILITY}

The data that support the findings of this study are available from health plan, but restrictions apply to the availability of these data, which were used under an agreement for the current study, and so are not publicly available. Data are however available from the authors upon reasonable request and with permission of the health plan.

\section{CODE AVAILABILITY}

The authors will make available upon reasonable request any previously unreported custom computer code or algorithm used to generate results that are reported in the paper and central to its main claims.

Received: 22 April 2020; Accepted: 5 January 2021; Published online: 15 February 2021

\section{REFERENCES}

1. O'Malley, A. S. \& Rich, E. C. Measuring comprehensiveness of primary care: challenges and opportunities. J. Gen. Intern. Med. 30, 568-575 (2015).

2. Starfield, B., Shi, L. \& Macinko, J. Contribution of primary care to health systems and health. Milbank Q. 83, 457-502 (2005).

3. Levine, D. M., Landon, B. E. \& Linder, J. A. Quality and experience of outpatient care in the United States for adults with or Without primary care. JAMA Intern. Med. https://doi.org/10.1001/jamainternmed.2018.6716 (2019).

4. Basu, S. et al. Association of primary care physician supply with population mortality in the United States, 2005-2015. JAMA Intern. Med. 179, 506 (2019).

5. Rhodes, K. V. et al. Primary care access for new patients on the eve of health care reform. JAMA Intern. Med. 174, 861-869 (2014). 
6. Hsiang, W. R. et al. Medicaid patients have greater difficulty scheduling health care appointments compared with private insurance patients: a meta-analysis. Inquiry 56, 004695801983811 (2019).

7. Diamant, A. L., Brook, R. H., Fink, A. \& Gelberg, L. Assessing use of primary health care services by very low-income adults in a managed care program. Arch. Intern. Med. 161, 1222-1227 (2001).

8. Levine, D., Linder, J. \& Landon, B. Characteristics of Americans with primary care and changes over time, 2002-2015. JAMA Intern. Med. 180, 463-466 (2020).

9. Decker, S. L. No association found between the medicaid primary care fee bump and physician-reported participation in medicaid. Health Aff. 37, 1092-1098 (2018).

10. Smulowitz, P. B., O'Malley, J., Yang, X. \& Landon, B. E. Increased use of the emergency department after health care reform in Massachusetts. Ann. Emerg. Med. 64, 107-115.e3 (2014)

11. Nikpay, S., Freedman, S., Levy, H. \& Buchmueller, T. Effect of the affordable care act medicaid expansion on emergency department visits: evidence from statelevel emergency department databases. Ann. Emerg. Med. 70, 215-225.e6 (2017).

12. Cheung, P. T., Wiler, J. L., Lowe, R. A. \& Ginde, A. A. National study of barriers to timely primary care and emergency department utilization among medicaid beneficiaries. Ann. Emerg. Med. 60, 4-10.e2 (2012).

13. Robotham, D., Satkunanathan, S., Reynolds, J., Stahl, D. \& Wykes, T. Using digital notifications to improve attendance in clinic: systematic review and metaanalysis. BMJ Open 6, e012116 (2016).

14. Kannisto, K. A., Koivunen, M. H. \& Välimäki, M. A. Use of mobile phone text message reminders in health care services: a narrative literature review. J. Med. Internet Res. 16, e222 (2014).

15. Percac-Lima, S., Singer, D. E., Cronin, P. R., Chang, Y. \& Zai, A. H. Can text messages improve attendance to primary care appointments in underserved populations? J. Health Care Poor Underserved 27, 1709-1725 (2016).

16. Gurol-Urganci, I., de Jongh, T., Vodopivec-Jamsek, V., Atun, R. \& Car, J. Mobile phone messaging reminders for attendance at healthcare appointments. Cochrane Database Syst. Rev. https://doi.org/10.1002/14651858.CD007458.pub3 (2013).

17. Leong, K. C. et al. The use of text messaging to improve attendance in primary care: a randomized controlled trial. Fam. Pract. 23, 699-705 (2006).

18. Junod Perron, $\mathrm{N}$. et al. Reduction of missed appointments at an urban primary care clinic: a randomised controlled study. BMC Fam. Pract. 11, 79 (2010).

19. Demographics of Mobile Device Ownership and Adoption in the United States Pew Research Center. http://www.pewinternet.org/fact-sheet/mobile/.

20. Rust, G. et al. Practical barriers to timely primary care access. Arch. Intern. Med. 168, 1705 (2008)

21. Linder, J. A. \& Levine, D. M. Health care communication technology and improved access, continuity, and relationships: the revolution will be uberized. JAMA Intern. Med. 176, 643-644 (2016).

22. Zallman, L., Bearse, A., West, C., Bor, D. \& McCormick, D. Patient preferences and access to text messaging for health care reminders in a safety-net setting. Inform. Health Soc. Care 42, 32-42 (2017).

23. Sharpe, S. et al. Effect of a text message intervention to reduce hazardous drinking among injured patients discharged from a trauma ward: a randomized controlled trial. npj Digit. Med. 1, 13 (2018).

24. Rand, C. M. et al. Effectiveness of centralized text message reminders on human papillomavirus immunization coverage for publicly insured adolescents. J. Adolesc. Health 56, S17-S20 (2015).

25. Danaher, B. G., Tyler, M. S., Crowley, R. C., Brendryen, H. \& Seeley, J. R. Outcomes and device usage for fully automated internet interventions designed for a smartphone or personal computer: the MobileQuit smoking cessation randomized controlled trial. J. Med. Internet Res. 21, e13290 (2019).

26. Herrett, E. et al. Text messaging reminders for influenza vaccine in primary care: a cluster randomised controlled trial (TXT4FLUJAB). BMJ Open 6, e010069 (2016).

27. Buis, L. et al. Text messaging to improve hypertension medication adherence in African Americans from primary care and emergency department settings: results from two randomized feasibility studies. JMIR mHealth uHealth 5, e9 (2017).

28. Junod Perron, $\mathrm{N}$. et al. Text-messaging versus telephone reminders to reduce missed appointments in an academic primary care clinic: a randomized controlled trial. BMC Health Serv. Res. 13, 125 (2013)

29. Thompson, J. H. et al. Developing patient-refined messaging for a mailed colorectal cancer screening program in a Latino-based Community Health Center. J. Am. Board Fam. Med. 32, 307-317 (2019).

30. Ahlers-Schmidt, C. R. et al. Content of text messaging immunization reminders: what low-income parents want to know. Patient Educ. Couns. 85, 119-121 (2011).

31. Loewenstein, G., Volpp, K. G. \& Asch, D. A. Incentives in health: different prescriptions for physicians and patients. JAMA 307, 1375-1376 (2012).

32. Leeb, A. et al. Using automated text messages to monitor adverse events following immunisation in general practice. Med. J. Aust. 200, 416-418 (2014).
33. Dowshen, N., Kuhns, L. M., Gray, C., Lee, S. \& Garofalo, R. Feasibility of interactive text message response (ITR) as a novel, real-time measure of adherence to antiretroviral therapy for HIV+ youth. AIDS Behav. 17, 2237-2243 (2013).

34. Haller, D. M., Sanci, L. A., Patton, G. C. \& Sawyer, S. M. Text message communication in primary care research: a randomized controlled trial. Fam. Pract. 26 325-330 (2009).

35. Sommers, B. D. \& Rosenbaum, S. Issues in health reform: how changes in eligibility may move millions back and forth between medicaid and insurance exchanges. Health Aff. 30, 228-236 (2011).

36. Baird, V. M. Initial Comprehensive Health Assessment. https://www.dhcs.ca.gov/ formsandpubs/Documents/MMCDAPLsandPolicyLetters/PL2008/PL08-003.PDF (2008).

37. Wilson, K. 2019 Edition-California's County-Based Health Plans. https://www. chcf.org/publication/2019-edition-californias-county-based-health-plans/ (2019).

38. Sussman, J. B. \& Hayward, R. A. An IV for the RCT: using instrumental variables to adjust for treatment contamination in randomised controlled trials. BMJ $\mathbf{3 4 0}$ c2073-c2073 (2010).

39. Baicker, K. et al. The Oregon experiment-effects of medicaid on clinical outcomes. N. Engl. J. Med. 368, 1713-1722 (2013).

\section{ACKNOWLEDGEMENTS}

The authors wish to thank the Medicaid plan for their collaboration and the California Health Care Foundation for supporting this work.

\section{AUTHOR CONTRIBUTIONS}

D.M.L. had full access to all of the data in the study and takes responsibility for the integrity of the data and the accuracy of the data analysis. D.M.L. and A.M. designed the study. All authors performed data analysis, interpretation, and critical revision D.M.L. drafted the manuscript and provided administrative, technical, and material support. P.K. performed statistical analysis. A.M. supervised the study. This study was previously presented at the New England regional meeting of the Society of General Internal Medicine in 2019.

\section{COMPETING INTERESTS}

P.K., D.M.L., and A.M. have no competing interests. D.M.L. wishes to disclose PIinitiated grant funding from Biofourmis for home hospital artificial intelligence research and software development and PI-initiated grant funding from IBM for COVID-19 artificial intelligence research, both unrelated to the current work.

\section{ADDITIONAL INFORMATION}

Supplementary information The online version contains supplementary material available at https://doi.org/10.1038/s41746-021-00389-5.

Correspondence and requests for materials should be addressed to D.M.L.

Reprints and permission information is available at http://www.nature.com/ reprints

Publisher's note Springer Nature remains neutral with regard to jurisdictional claims in published maps and institutional affiliations.

Open Access This article is licensed under a Creative Commons Attribution 4.0 International License, which permits use, sharing, adaptation, distribution and reproduction in any medium or format, as long as you give appropriate credit to the original author(s) and the source, provide a link to the Creative Commons license, and indicate if changes were made. The images or other third party material in this article are included in the article's Creative Commons license, unless indicated otherwise in a credit line to the material. If material is not included in the article's Creative Commons license and your intended use is not permitted by statutory regulation or exceeds the permitted use, you will need to obtain permission directly from the copyright holder. To view a copy of this license, visit http://creativecommons. org/licenses/by/4.0/.

(c) The Author(s) 2021 